\title{
Avanços e percalços na elaboração da legislação nacional sobre acesso a recursos genéticos e aos conhecimentos tradicionais associados*
}

\section{Difficulties and Advances in the Development of National Legislation as to the Access to Genetic Resources and Associated Traditional Knowledge}

\author{
Rosemary de Sampaio GODINHO** \\ Carlos José Saldanha MACHADO***
}

\begin{abstract}
RESUMO
O marco legal que regulamenta o acesso ao patrimônio genético, aos conhecimentos tradicionais associados, à tecnologia, à transferência de tecnologia para sua utilização e conservação e a repartição de benefícios no Brasil é uma Medida Provisória. Medidas Provisórias, em nosso ordenamento jurídico, são atos normativos com força de lei, que podem ser adotados pelo Presidente da República em casos de relevância e urgência. O caráter provisório da legislação que regula o tema perdura há dez anos, ainda sem data prevista para a edição da lei que a substitua. Em 2003, a Câmara Técnica Legislativa do Conselho de Gestão do Patrimônio Genético (CGEN) coordenou a elaboração de um anteprojeto de lei com o objetivo de substituir a Medida Provisória e regulamentar o Tratado Internacional sobre Recursos Fitogenéticos para a Alimentação e a Agricultura, aprovado pela Organização das Nações Unidas para a Alimentação e Agricultura em 2001 e ratificado pelo Brasil em 2006. O APL foi encaminhado à Casa Civil e, após alguns debates, foi submetido à consulta pública em 2007. Atualmente, o referido anteprojeto de lei se encontra na Casa Civil à espera de ser encaminhado pela Presidente da República ao Congresso Nacional. O objetivo deste estudo é realizar uma análise comparativa entre este anteprojeto de lei - elaborado pelo CGEN e que foi submetido à consulta pública pela Casa Civil - e a Medida Provisória 2.186-16/01, apontando os avanços obtidos e os pontos que ainda devem ser aperfeiçoados.
\end{abstract}

Palavras-chave: anteprojeto de lei; acesso ao patrimônio genético; conhecimentos tradicionais associados.

\footnotetext{
"Esse artigo é uma versão ampliada e modificada do trabalho "Lei e Ordem no Acesso das Ciências à Diversidade Biológica e aos Conhecimentos Tradicionais", apresentado oralmente no XV Congresso Brasileiro de Sociologia, no dia 28 de julho de 2011 - UFPR, Curitiba-PR. Agradecemos à Coordenação de Aperfeiçoamento de Pessoal de Nível Superior - CAPES pelo auxílio financeiro.

** Doutoranda do Programa Pós-Graduação em Meio Ambiente da Universidade do Estado do Rio de Janeiro (PPG-MA/UERJ). Bolsista CAPES. Email: rosegodinho@globo.com

*** Doutor em Antropologia pela Université Paris Descartes, França. Professor do PPG-MA/UERJ e pesquisador da Fundação Oswaldo Cruz e do Conselho Nacional de Desenvolvimento Científico e Tecnológico. Email: saldanha@fiocruz.br
} 


\begin{abstract}
The legal framework regulating access to genetic resources, to associated traditional knowledge, to technology, to technology transfer for its use and conservation and to the benefit sharing in Brazil is a provisional or Interim measure. Interim Measures in our legal normative acts have the force of law, which can be adopted by the President in cases of urgency and relevance. The provisional character of the legislation regulating the issue has been lingering for ten years, and there is still no date for issuing the law that will replace it. In 2003 the Technical Board's Legislative Council for the Management of Genetic Heritage (CGEN) coordinated the preparation of a draft bill, aiming to replace the Provisional and to regulate the International Treaty on Plant Genetic Resources for Food and Agriculture, adopted by the UN Food and Agriculture in 2001 and ratified by Brazil in 2006. The APL was sent to the Casa Civil and after some discussion it was subject to public consultation in 2007. Currently, the APL is at the Casa Civil waiting to be forwarded to the Congress by the President. The aim of this study is a comparative analysis between the draft bill prepared by CGEN, which was submitted to public consultation by the Casa Civil, and the Provisional 2.186-16/01, highlighting the progress made and the points that still need refinement.
\end{abstract}

Key-words: draft bill; access to genetic heritage; associated traditional knowledge.

\section{Introdução}

A organização não governamental norte-americana Conservation International apresentou, em 1998, um mapa dos 17 países detentores da maior diversidade biológica do planeta, onde o Brasil lidera a lista, seguido de Colômbia, Indonésia, China, México e outros ${ }^{1}$ (SZPILMAN, 1998). Tal liderança certamente se deve ao fato de o Brasil abrigar em seu território aproximadamente $13 \%$ de toda a biota do planeta (LEWINSOHN; PRADO, 2005). Entretanto, o Brasil não é apenas megadiverso biologicamente e o seu pluralismo cultural também é de grande expressão. São cerca de 216 etnias e 180 línguas indígenas, representando a maior densidade linguística da América do Sul (SANTILLI, 2005).

Somente a partir da realização da Conferência das Nações Unidas para o Meio Ambiente e o Desenvolvimento (Rio-92), onde foi elaborada a Convenção sobre Diversidade Biológica (CDB), é que se alterou a natureza jurídica da diversidade biológica, passando de res nullius a objeto juridicamente tutelado.

Este tratado internacional propõe inúmeras inovações, que tornam a sua implantação bastante complexa, o que, de acordo com Azevedo (2002), significa um grande desafio às partes signatárias. Essa pode ser uma das explicações para a ausência de legislação interna sobre o tema em vários países que ratificaram a $\mathrm{CDB}$.
Um dos grandes desafios propostos pela CDB é a necessidade de se proteger as populações tradicionais, indígenas e não indígenas, bem como os seus conhecimentos tradicionais associados à biodiversidade. Tais populações passaram a ocupar um lugar de destaque no cenário mundial, principalmente após o fenômeno da globalização, que tornou a necessidade de proteção ao meio ambiente, onde essas comunidades estão inseridas, uma questão essencial para o futuro não só da espécie humana, como também para todo o planeta.

O Brasil faz parte da minoria que já elaborou um marco legal para o acesso ao patrimônio genético, a proteção e o acesso ao conhecimento tradicional associado, a repartição de benefícios e o acesso à tecnologia e transferência de tecnologia para sua conservação e utilização. A norma que disciplina o tema em âmbito federal é a Medida Provisória 2186-16, de 23 de agosto de 2001, que regulamenta o inciso II do $\S 1^{\circ}$ e o $\S 4^{\circ}$ do artigo 225 da Constituição Federal de 1988 , e os artigos $1^{\circ}, 8^{\circ}$ alínea “j”, 10 alínea “c", 15 e 16 itens " 3 " e " 4 " da Convenção sobre Diversidade Biológica.

Superar o caráter provisório dessa legislação que apresenta várias imperfeições técnicas é um dos maiores desafios para o governo brasileiro, uma vez que somente uma legislação definitiva poderá coibir a biopirataria e garantir a atração de investimentos nesse setor para o país.

Paralelamente a esses acontecimentos, a Organização das Nações Unidas para a Alimentação e Agricultura apro-

${ }^{1}$ Ranking da Biodiversidade em ordem decrescente: Brasil, Colômbia, Indonésia, China, México, África do Sul, Venezuela, Equador, Peru, Estados Unidos, Papua-Nova Guiné, Índia, Austrália, Malásia, Madagascar, República do Congo, Filipinas. 
vou, em 2001, o Tratado Internacional sobre os Recursos Fitogenéticos para a Alimentação e a Agricultura. No Brasil, esse Tratado entrou em vigor em 2006, todavia seu conteúdo ainda não foi regulamentado pela legislação interna. Santilli (2009) esclarece com propriedade que o regime de acesso e repartição de benefícios estabelecido pela MP 2.186-16/01 não considera as especificidades dos recursos fitogenéticos utilizados para a alimentação e a agricultura. Entretanto, na falta de uma legislação específica sobre o tema, a Medida Provisória se aplica tanto aos recursos genéticos silvestres como aos domesticados.

Em 2003, o Conselho de Gestão do Patrimônio Genético coordenou a discussão de uma nova proposta para substituir a MP 2.186-16/01, elaborando-se aí o anteprojeto de lei (APL), que foi enviado no mesmo ano pela então Ministra do Meio Ambiente à Casa Civil, onde teve início uma nova discussão envolvendo os ministérios interessados. A partir dessa discussão, ficou garantido que o acesso aos recursos genéticos e aos conhecimentos tradicionais da agrobiodiversidade faria parte do escopo do referido anteprojeto de lei.

O APL em questão dispõe sobre a coleta de material biológico, o acesso aos recursos genéticos e seus derivados para pesquisa científica ou tecnológica, bioprospecção ou elaboração ou desenvolvimento de produtos comerciais, a remessa e o transporte de material biológico, o acesso e a proteção aos conhecimentos tradicionais associados e aos direitos dos agricultores, e a repartição de benefícios.

O objetivo desse estudo é realizar uma análise comparativa entre este anteprojeto de lei elaborado pelo Conselho de Gestão do Patrimônio Genético (CGEN) para substituir a MP 2186-16/01, que foi submetido à consulta pública pela Casa Civil em 2007, e a própria Medida Provisória, apontando os avanços obtidos e os pontos que ainda devem ser aperfeiçoados. Para tanto, utilizou-se o texto do anteprojeto de lei disponibilizado para consulta pública pela Casa Civil².

Com o intuito de fornecer uma melhor compreensão sobre o assunto, o trabalho foi dividido em oito seções. Inicialmente, apresenta um histórico sobre a gênese, em nosso país, da legislação ora tratada.

Após essa apresentação histórica, passa-se a enfocar questões específicas do APL, como a submissão à consulta pública e a adoção do Princípio da Precaução.
Posteriormente, são demonstradas as tentativas de saneamento de problemas conceituais trazidos pela Medida Provisória 2.186-16/01 e o enfoque dado pelo APL à agrobiodiversidade.

Em seguida, são apresentadas as inovações propostas pelo anteprojeto de lei que não são previstas na MP e a falta de previsão de penas restritivas de liberdade no rol de sanções apresentadas pelo APL.

Ao final, pode-se concluir que, mesmo apresentando avanços, o APL é alvo de inúmeras críticas, ficando evidente o conflito de interesses dos diversos setores da sociedade envolvidos no tema do anteprojeto de lei.

\section{Histórico}

Machado e Godinho (2011) ressaltam que após a aprovação da Convenção sobre a Diversidade Biológica, durante a Conferência das Nações Unidas sobre Meio Ambiente, em 1992, por diversas nações, inclusive o Brasil, ficou evidente a necessidade de uma lei que regulamentasse o acesso aos nossos recursos genéticos e biológicos. Tentando suprir tal lacuna, a então Senadora Marina Silva (PT-AC) apresentou, em 1995, um projeto de lei sobre o tema (PL 306/95), cujo substitutivo apresentado pelo Senador Osmar Dias (PSDB-PR) foi aprovado por unanimidade na Comissão de Assuntos Sociais do Senado, em 1998 (PL 4.842/98), e encaminhado à Câmara dos Deputados. A tramitação de tal projeto de lei contou com a realização de diversas audiências públicas, das quais participaram lideranças populares e indígenas, organizações não governamentais, cientistas e membros do governo.

No mesmo ano de 1998, o deputado Jacques Wagner (PT-BA) encaminhou novo projeto de lei à Câmara dos Deputados (PL 4.579/98) e o Poder Executivo também apresentou o seu próprio projeto na Câmara dos Deputados (PL 4.751/98), além de uma proposta de emenda à Constituição (PEC n ${ }^{\circ}$ 618/98) que inclui nos bens da União o patrimônio genético, exceto o humano. Com esta proposta do governo, ao lado do projeto do deputado Jacques Wagner, o projeto do Senado permaneceu dois anos estacionado na Câmara dos Deputados.

Bensusan (2003) destaca que o PL 4.751/98 previa autorização de acesso aos recursos genéticos apenas para

\footnotetext{
${ }^{2}$ Texto disponível em: <http://www.planalto.gov.br/ccivil_03/consulta_publca/consulta_biologica.htm>.
} 
instituições nacionais. As instituições estrangeiras que desejassem desenvolver pesquisas sobre o tema só poderiam fazê-lo se vinculadas a uma instituição nacional pública.

Em maio de 2000, a Bioamazônia - uma Organização Social - assinou um contrato com a empresa multinacional farmacêutica de origem suíça Novartis Pharma AG, que daria a esta empresa direito de acesso e uso exclusivos de material genético pertencente ao vasto e riquíssimo território amazônico. O contrato foi denunciado, por conta de suas inúmeras irregularidades, e levou o então Ministro do Meio Ambiente, José Sarney Filho, a recomendar a sua suspensão, entre outros motivos, pelo fato de o Brasil não possuir, na época, legislação específica para garantir sua soberania sobre seus próprios recursos genéticos.

A repercussão do caso precipitou a edição de uma Medida Provisória, ato do Poder Executivo com força de lei, MP n ${ }^{\circ}$ 2052-1, de 29 de junho de 2000, dispondo sobre "a proteção e o acesso ao conhecimento tradicional associado, a repartição de benefícios e o acesso à tecnologia e à transferência tecnológica para sua conservação e utilização", sobrepondo-se a toda discussão que vinha sendo travada no Congresso Nacional sobre a matéria, além de não aproveitar os resultados dos debates já realizados.

A primeira versão da medida provisória, que foi reeditada sem alterações sucessivamente até abril de 2001, continha vários pontos polêmicos, que foram questionados judicialmente no Supremo Tribunal Federal (STF) por duas Ações Diretas de Inconstitucionalidade (ADI). Por conta da relevância do conteúdo dessas ADIs, as reedições posteriores da Medida Provisória sofreram significativas alterações em seu conteúdo, o que levou o STF a extinguir as ações por falta de objeto.

Sobre as reedições da Medida Provisória em análise, Castilho (2003) esclarece que, a partir de maio de 2001, as reedições passaram a ter o texto alterado, o que ocorreu até agosto do mesmo ano. A partir daí, por força da Emenda Constitucional $\mathrm{n}^{\circ} 32$, de 12/09/2001, as medidas provisórias editadas em data anterior continuam em vigor até que medida provisória ulterior as revogue explicitamente ou até deliberação definitiva do Congresso Nacional. Assim, o acesso ao conhecimento tradicional de recursos genéticos no Brasil está regulado pela Medida Provisória nº 2.186-16, de 23 de agosto de 2001, em sua $16^{\text {a }}$ reedição, deixando inseguros todos os interessados no tema, diante da vulnerabilidade deste ato normativo com força de lei.

Em agosto de 2000, o Projeto de Lei 4.751/98 do Poder Executivo foi por ele retirado de tramitação e arquivado pela mesa diretora da Câmara dos Deputados.
A partir de 2003, alguns Projetos de Lei versando sobre o tema foram propostos e apensados ao PL 4.842/98, que já tinha em apenso o PL 4.579/98. São eles: PL 2.360/2003, de autoria do Deputado Mário Negromonte (PP-BA), que dispõe sobre a pesquisa ou a coleta de amostras da flora brasileira; PL 5.078/2005, de autoria do Deputado Eduardo Valverde (PT-RO), que estabelece e regulamenta os mecanismos para a proteção, promoção, reconhecimento e exercício da medicina tradicional, das terapias complementares e do patrimônio biogenético das populações indígenas e dá outras providências; PL 287/2007, de autoria da Deputada Janete Capiberibe (PSB/AP), que proíbe a exportação de espécies vegetais, germoplasma, produto e subproduto de origem vegetal, sem licença do IBAMA. Penaliza o infrator com pena de reclusão, alterando a Lei $n^{\circ}$ 9.605, de 1998; PL 3.170/2008, de autoria do Deputado Hidekazu Takayama (PSC/PR), que acrescenta dispositivo à Lei $\mathrm{n}^{\circ} 4.771 / 65$ (Código Florestal), permitindo a retirada de folhas verdes ou secas com características farmacológicas comprovadas; PL 7.709/2010, de autoria do Deputado Ricardo Tripoli (PSDB/ SP), que altera e inclui dispositivos na Medida Provisória $n^{\circ}$ 2.186/01, alterando a composição do Conselho de Gestão, instituindo prazos para a emissão de licenças, combater a biopirataria e regular a repartição equânime dos benefícios, prevenindo condutas lesivas à conservação do patrimônio genético e dá outras providências; PL 7.710/2010, também de autoria do Deputado Ricardo Tripoli (PSDB/SP), que dispõe sobre a criminalização de condutas lesivas à conservação da biodiversidade, à proteção e à utilização sustentável do patrimônio genético, cominando sanções penais e dando outras providências.

A situação atual do PL 4.842/98, com todos os seus apensos, é que este se encontra no aguardo da constituição de comissão especial para efetuar novamente a sua análise.

Em relação à PEC 618/98, em 2009 foi criada uma comissão especial destinada a apreciar e a proferir um parecer sobre a mesma.

Em março de 2003, a Ministra Marina Silva assume o Ministério do Meio Ambiente. Logo no início de seu mandato, a Ministra realizou um seminário para definir qual seria o melhor caminho para a reformulação da legislação relacionada ao acesso a recursos genéticos e à proteção aos conhecimentos tradicionais, uma vez que havia uma percepção clara de todos os segmentos afetos ao tema da não adequação do escopo da Medida Provisória 2.186-16/01 e da necessidade de revisão do arcabouço legal. Neste evento, ficou decidido que o melhor a ser feito seria a elaboração de um novo projeto de lei. 
Coube então à Câmara Técnica Legislativa do Conselho de Gestão do Patrimônio Genético (CGEN) coordenar o processo, que se estendeu de julho a outubro de 2003. Segundo Fontes (2004), além de todos os órgãos governamentais do CGEN, diversos setores da sociedade civil participaram da elaboração do anteprojeto de lei, entre eles a Sociedade Brasileira para o Progresso da Ciência (SBPC), a Associação Brasileira de Antropologia (ABA), o Conselho Empresarial para o Desenvolvimento Sustentável (CEBDS) e a Associação Brasileira de Organizações Não Governamentais (ABONG). Em novembro deste mesmo ano, o anteprojeto de Lei (APL) foi enviado pelo Ministério do Meio Ambiente à Casa Civil.

Entre 2004 e 2007, o APL foi debatido entre os diversos órgãos governamentais sob a articulação da Casa Civil, entre eles os Ministérios do Meio Ambiente (MMA), da Ciência e Tecnologia (MCT), da Agricultura, Pecuária e Abastecimento (MAPA) e do Desenvolvimento, Indústria e Comércio Exterior (MDIC), que possuíam interesses no tema do referido anteprojeto de lei. Nesse debate, devido a algumas pressões, ficou garantida, segundo Novion e Mathias (2007), uma divisão artificial do sistema de acesso, entre recursos da biodiversidade e recursos da agrobiodiversidade utilizados em alimentação e agricultura, conferindo competências institucionais para regular setores economicamente relevantes, sem controle social ou espaço de interlocução.

Em novembro de 2007, o novo texto do APL foi submetido à consulta pública e as sugestões deveriam ser encaminhadas por meio de correspondência ou pela internet. A princípio, o prazo para esta consulta seria até fevereiro de 2008; entretanto, após algumas reivindicações sobre o curto espaço de tempo para se discutir um tema complexo e importante como este, ela foi prorrogada até julho desse mesmo ano.

Finda a consulta pública, a Casa Civil analisou os dados recebidos e os consolidou em outubro de 2008. O que se esperava é que, a partir de então, o APL estivesse pronto para ser encaminhado pelo Presidente da República ao Congresso Nacional. Entretanto, o que ocorreu foi a retirada do anteprojeto de lei da Casa Civil pelo Ministério do Meio Ambiente, que neste momento já não era mais chefiado pela Ministra Marina Silva e sim pelo Ministro Carlos Minc, para a elaboração de um novo texto, baseado nas propostas recebidas pela consulta pública.

Em setembro de 2009, os então ministros da Ciência e Tecnologia, Sergio Rezende, e do Meio Ambiente,
Carlos Minc, assinaram um Aviso endereçado à então ministra-chefe da Casa Civil, Dilma Roussef, solicitando encaminhamento do anteprojeto ao Congresso Nacional, na forma de projeto de lei. Note-se que neste momento o Ministério da Agricultura, Pecuária e Abastecimento não é citado. De acordo com informações da Pró-Reitoria de Pesquisa da Unicamp (PRP/PATGEN, 2010), na verdade foram encaminhados dois anteprojetos de lei à Casa Civil, um de autoria do MMA em parceria com o MCT e outro do MAPA, referente exclusivamente aos recursos genéticos para a agrobiodiversidade.

$\mathrm{O}$ anteprojeto de lei até o momento não foi encaminhado ao Congresso Nacional, permanecendo na Casa Civil.

\section{Submissão à consulta pública}

A primeira crítica feita ao anteprojeto de lei, na verdade, não diz respeito ao seu conteúdo, mas sim à forma como este foi submetido à consulta pública. Novion e Mathias (2007) salientam que a realização de uma consulta por correspondência ou pela internet apenas reforçou a forma pouco participativa que tem caracterizado a atuação do governo na elaboração da política nacional de acesso à biodiversidade, repartição de benefícios, proteção de conhecimentos tradicionais e direitos de agricultores.

Os autores enfatizam ainda que, devido à complexidade do conteúdo do projeto, o prazo estabelecido inicialmente para a consulta pública era extremamente curto para discussão e formação de opinião, além da necessidade de audiências públicas presenciais com povos indígenas, comunidades locais e agricultores familiares em diferentes regiões do Brasil que não possuem acesso à internet.

As reivindicações foram atendidas em parte pela Casa Civil e o prazo da consulta foi ampliado até julho do mesmo ano, mas as audiências públicas presenciais não foram realizadas.

\section{Princípio da Precaução}

A Constituição da República Brasileira de 1988, em seu artigo $225, \S 3^{\circ}$ prevê o Princípio da Precaução, que se tornou a base para o sistema jurídico de tutela do meio ambiente em todas as suas esferas - cível, administrativa e penal.

O Princípio da Precaução pode ser definido como aquele segundo o qual o risco de dano significativo ao meio 
ambiente, ainda que não reconhecido com absoluta certeza, obriga a atitudes imediatas de precaução (KISHI, 2004) para evitar o evento potencialmente danoso, utilizando-se o conjunto de conhecimentos científicos disponíveis.

Tal princípio começou a ser considerado internacionalmente nas questões ambientais a partir da Declaração de Estocolmo sobre o Ambiente Humano, de 1972. A partir daí, outras declarações e convenções internacionais incluíram entre os seus postulados o princípio da precaução, por exemplo, o Princípio 15 da Declaração do Rio de Janeiro sobre o Meio Ambiente e Desenvolvimento:

De modo a proteger o meio ambiente, o Princípio da Precaução deve ser amplamente observado pelos Estados, de acordo com suas capacidades. Quando houver ameaça de danos sérios ou irreversíveis, a ausência de absoluta certeza científica não deve ser utilizada como razão para postergar medidas eficazes e economicamente viáveis para prevenir a degradação ambiental ${ }^{3}$.

O Princípio da Precaução está presente também no preâmbulo da Convenção sobre Diversidade Biológica:

Observando também que quando exista ameaça de sensível redução ou perda de diversidade biológica, a falta de plena certeza científica não deve ser usada como razão para postergar medidas para evitar ou minimizar essa ameaça.

Em vista do exposto e considerando que o Brasil é signatário da $\mathrm{CDB}$, o que se deveria esperar sobre uma legislação nacional regulamentando qualquer assunto referente a Meio Ambiente e Biodiversidade era a adoção do Princípio da Precaução pela mesma.

Entretanto, não é isso que se observa no capítulo das disposições gerais da MP 2.186-16/01, em seu artigo $6^{\circ}$ :

A qualquer tempo, existindo evidência científica consistente de perigo de dano grave e irreversível à diversidade biológica, decorrente de atividades praticadas na forma desta Medida Provisória, o Poder Público, [...] determinará medidas destinadas a impedir o dano, [...].
Assim, além de violar previsão constitucional, a medida provisória prescreve justamente o contrário do veiculado em tratados internacionais assinados pelo Brasil e ratificados pelo Congresso Nacional, o que demonstra a sua falta de sintonia com documentos de incontestável relevância sobre o tema.

Nesse sentido, o anteprojeto de lei avança ao prever em seu artigo $6^{\circ}$, I, a aplicação do Princípio da Precaução. Machado (2009) sabiamente esclarece que este princípio visa à durabilidade da sadia qualidade de vida das gerações humanas e à continuidade da natureza existente no planeta, sem, contudo, imobilizar as atividades humanas.

\section{Problemas conceituais}

\section{Fim do termo patrimônio genético}

$\mathrm{O}$ anteprojeto adota o termo recurso genético no lugar de patrimônio genético utilizado pela Medida Provisória. O termo patrimônio genético é retirado inclusive da designação do CGEN, que a Medida Provisória batizou de Conselho de Gestão do Patrimônio Genético. Pelo APL, o CGEN passará a se chamar Conselho de Gestão dos Recursos Genéticos, mantendo, entretanto, a mesma sigla.

A adoção do termo recurso genético no lugar de patrimônio genético vai de encontro com a terminologia utilizada pela legislação internacional, como a $\mathrm{CDB}$, até porque possui um alcance mais abrangente, Como salienta Castilho (2003), o termo "recurso" alcança toda e qualquer posse, independente de constituir ou não um patrimônio.

$\mathrm{O}$ anteprojeto de lei define os recursos genéticos e seus derivados como "bens de uso comum do povo, cabendo ao poder público a gestão de seu uso, nos termos do disposto no APL, sem prejuízo dos direitos de comunidades indígenas, quilombolas ou tradicionais detentoras desses conhecimentos". O Programa de Política e Direito Socioambiental (2004) acredita que, com essa definição, o anteprojeto de lei avança em relação à Medida Provisória 2.186-16/01, que é omissa quanto à titularidade do patrimônio genético, além de entrar em consonância com a Constituição Federal, que define, no seu artigo 225, meio ambiente, incluindo o patrimônio genético como um "bem de uso comum do povo e essencial à sadia qualidade de vida". Em outras palavras, 
um bem pertencente à sociedade como um todo, mas que não pode ser apropriado por nenhum sujeito de direito individualmente, seja público ou privado.

\section{Comunidade tradicional toma o lugar da comunidade local}

Em contrapartida, o APL adota o termo comunidade tradicional, divergindo agora da Medida Provisória e da $\mathrm{CDB}$, que adotam o termo comunidade local. Apesar desse desalinhamento, o novo conceito deixa explícito o autorreconhecimento e retira do texto a exigência imposta pela Medida Provisória de a comunidade ter que se organizar tradicionalmente por gerações sucessivas para que possa estar protegida pelo manto do instrumento legal, o que causa muitas dúvidas a respeito de quantas gerações sucessivas serão necessárias para que a comunidade possa ser considerada local, além da dificuldade de comprovação dessas sucessivas gerações, visto que muitas comunidades não possuem documentação probatória.

Vale ressaltar que a definição trazida pelo APL é a mesma que já está prescrita no Decreto $n^{\circ} 6.040 / 2007$, que institui a política nacional de desenvolvimento sustentável dos povos e comunidades tradicionais, o que demonstra uma sintonia com a legislação já em vigor. Pereira e Diegues (2010) destacam que ainda não há uma definição aceita universalmente, por conta de diversos problemas relacionados às políticas ambientais, territoriais e tecnológicas. Entretanto, os autores ressaltam que uma definição universal facilitaria a proteção dos conhecimentos tradicionais dessas comunidades.

\section{Conhecimento tradicional e conhecimento tradicional disseminado}

Em relação ao conceito de conhecimento tradicional associado, o anteprojeto de lei traz um conceito mais amplo em relação à Medida Provisória, incluindo a inovação, se colocando em concordância com o estabelecido na Convenção sobre Diversidade Biológica e pela Organização Mundial de Propriedade Intelectual (OMPI).
Outro aspecto que merece destaque é que, enquanto a MP 2.186-16/01 vincula o conhecimento tradicional associado ao patrimônio genético apenas, o APL, mais corretamente, o associa à Diversidade Biológica, seguindo novamente o que preceitua a CDB em seu artigo 8, “j”4.

Existe ainda no anteprojeto de lei a previsão da manutenção e proteção do conhecimento tradicional associado, mesmo que este se encontre fora da comunidade, como em banco de dados, inventários culturais, publicações e no comércio. Tal dispositivo não tem similar na Medida Provisória.

Relevante também é a distinção feita pelo anteprojeto de lei entre conhecimento tradicional associado e disseminado, sendo este último considerado aquele que já se encontra difundido na sociedade, de uso livre de todos, não sendo mais reconhecido como associado diretamente à cultura de comunidades indígenas, quilombolas ou tradicionais. $\mathrm{O}$ fato de o APL ter feito tal distinção já constitui um avanço em relação à MP 2.186-16/01, uma vez que, ao estabelecer uma proteção contra a apropriação indevida dos conhecimentos tradicionais associados, ela não define claramente, conforme salientam Ferreira e Clementino (2006), a que conhecimento tradicional quis se referir, se aquele obtido por acesso direto ou indireto, tampouco determinou como diferenciar o conhecimento tradicional objeto de proteção daquele incorporado pela evolução de uma sociedade sociodiversa como a brasileira.

Entretanto, o conceito de conhecimento tradicional disseminado trazido pelo APL diverge do conceito estabelecido por Kamau (2009):

Conhecimento tradicional mantido de forma privada por entidades isoladas ou alienadas de comunidades locais ou indígenas que utilizam o conhecimento tradicional para auferir ganhos de maneira privada sem o reconhecimento das comunidades indígenas e locais e sua total exclusão na repartição de benefícios.

Segundo o autor, seriam os conhecimentos mantidos por médicos especialistas em medicina tradicional, ervatários, pesquisadores e institutos de pesquisas, além daqueles divulgados em publicações.

\footnotetext{
${ }^{4}$ CDB - Artigo 8: “Cada parte contratante deve, na medida do possível e conforme o caso: [...]

j) Em conformidade com sua legislação nacional, respeitar, preservar e manter o conhecimento, inovações e práticas das comunidades locais e populações indígenas com estilo de vida tradicionais relevantes à conservação e à utilização sustentável da diversidade biológica e incentivar sua mais ampla aplicação com a aprovação e a participação dos detentores desse conhecimento, inovações e práticas; e encorajar a repartição equitativa dos benefícios oriundos da utilização desse conhecimento, inovações e práticas.” Disponível em: <http://www.mma.gov.br/estruturas/sbf_chm_rbbio/_arquivos/cdbport_72.pdf>. Acesso em: 25/03/2011.
} 
Kishi (2011), ao analisar a definição estabelecida no anteprojeto de lei, salienta a dificuldade em se esclarecer o alcance de conhecimento tradicional não reconhecido como sendo associado "diretamente" à cultura das comunidades. Para a autora, fica a dúvida se um conhecimento tradicional disseminado não for difundido em toda a sociedade brasileira, uma vez ser o Brasil um país continental, estará ao abrigo da proteção do APL.

\section{Consentimento prévio fundamentado no lugar de anuência prévia}

A Medida Provisória 2.186-16/01, em seu artigo 16, $\S 9^{\circ}$ que trata de acesso e remessa de componentes de patrimônio genético e de conhecimentos tradicionais associados, especifica que somente será concedida a autorização para o acesso e a remessa após a anuência prévia de diversos atores elencados em cinco incisos, mas não estabelece como deverá ser tal anuência, sob que condições e quais critérios deverão ser utilizados. Por essas razões, e por estar em descompasso com o termo utilizado nos documentos internacionais, que é o consentimento prévio informado, vários doutrinadores - entre eles Castilho (2004) - criticaram veementemente a adoção do termo anuência prévia pela Medida Provisória.

O texto do anteprojeto de lei, nesse sentido, foi mais positivo, primeiro por não utilizar o termo anuência prévia e sim consentimento prévio fundamentado e, segundo, porque o define no artigo que dedica às definições dos termos empregados no texto.

Pela definição do APL, consentimento prévio fundamentado é aquele esclarecido e formal, previamente dado por comunidade indígena, quilombola ou tradicional, representada segundo seus usos, costumes e tradições. Já o consentimento prévio informado, de acordo com Castilho (2004), considera que aquele que consente deve ser informado, em linguagem que lhe seja acessível culturalmente, das consequências econômicas, jurídicas e políticas do seu ato.

Nesse sentido, Kishi (2009) esclarece que o consentimento prévio fundamentado não deve se resumir a uma anuência curta e simples, ao contrário, deve ser um processo que englobe intensas trocas de informações para a elucidação do projeto por meio de reuniões e palestras.

A definição do anteprojeto de lei ainda não expressa corretamente o que vem a ser o princípio do consentimento prévio informado, incorporado na Convenção sobre a Diversidade Biológica, podendo, nesse sentido, sofrer alterações.
A representatividade das comunidades tradicionais no consentimento prévio informado deve ser realizada por elas mesmas, no exercício do direito fundamental à autodeterminação, consolidado no artigo $4^{\circ}$, III da Constituição Federal. Tal direito garante a legitimidade tanto das comunidades indígenas quanto das demais comunidades tradicionais para fornecer o consentimento prévio informado (KISHI, 2009).

Dessa maneira, enfatiza a autora supracitada, as comunidades tradicionais devem ser representadas por elas próprias ou por suas organizações, respeitando seus valores culturais e tradições, prescindindo de serem representadas por algum órgão tutor ou curador.

\section{Diferenças entre coleta e acesso}

Após a edição da Medida Provisória 2.186-16/01, uma das inúmeras dúvidas levantadas sobre o seu texto estava relacionada aos conceitos de acesso e coleta, levando inclusive ao estabelecimento da primeira Orientação Técnica do CGEN, que define acesso e o diferencia de coleta. De acordo com tal definição, o acesso está restrito ao nível genético, molecular ou de substâncias provenientes do metabolismo de seres vivos e de extratos obtidos destes organismos; já a coleta refere-se à retirada do organismo, no todo ou em parte, de condições in situ. Nesse sentido, o anteprojeto de lei seguiu o conceito estabelecido na Orientação Técnica ${ }^{\circ} 1$ do CGEN e diferenciou claramente coleta e acesso, colocando-os, inclusive, em capítulos distintos.

Entretanto, o Conselho Técnico Científico do Museu Paraense Emílio Goeldi, após debater o texto do APL, concluiu que este repete o erro da Medida Provisória 2.186-16/01 ao confundir atividades distintas como se fossem uma matéria única. De acordo com este Conselho, a MP mescla de forma arbitrária a bioprospecção com fins comerciais com atividades puramente acadêmicas e, com isso, criminaliza a busca de informações fundamentais para o correto gerenciamento da biodiversidade brasileira (VIEIRA, 2008).

Nesse sentido, o Conselho Técnico Científico do Museu Goeldi sugeriu o desdobramento em, no mínimo, duas propostas de legislação distintas, uma que verse apenas sobre coleta e transporte de material biológico para fins puramente científicos e acadêmicos e uma segunda proposta versando sobre os demais aspectos da biodiversidade, que, no parecer do Conselho, são bem mais complexos. 


\section{Agrobiodiversidade}

Santilli (2009) enfatiza que o regime de acesso e repartição de benefícios estabelecido pela Medida Provisória 2.186-16/01 foi concebido principalmente para os recursos genéticos silvestres, sem considerar as especificidades dos recursos fitogenéticos utilizados para a alimentação e a agricultura. Entretanto, ela se aplica tanto aos recursos genéticos silvestres como aos domesticados e não faz distinção entre os dois para fins de acesso e repartição de benefícios.

Visando preencher esta lacuna, o anteprojeto de lei incluiu em seu escopo o direito dos agricultores e dedica capítulos exclusivos aos recursos genéticos provenientes da agrobiodiversidade e ao conhecimento tradicional associado relevante à alimentação e agricultura. Entretanto, o APL mantém o regime bilateral dos contratos, o que, segundo a autora supracitada, é incompatível para os recursos fitogenéticos para a alimentação e agricultura, uma vez que qualquer variedade agrícola local é o resultado de atividades de seleção e melhoramento desenvolvidas ao longo de muitas gerações de agricultores e a agrobiodiversidade é fruto do manejo complexo e dinâmico dos cultivos agrícolas realizado pelos agricultores.

\section{Inovações do anteprojeto de lei}

\section{Criação de três Cadastros Nacionais de Material Biológico e de Recurso Genético}

O APL cria três cadastros nacionais de material biológico e de recurso genético. São eles:

1) O Cadastro Nacional de Controle de Atividades de Pesquisa Científica ou Tecnológica de Recursos Genéticos - CNACT, que deverá ser implementado e administrado pelo MCT, por intermédio do Conselho Nacional de Desenvolvimento Científico e Tecnológico (CNPq). Este cadastro será destinado ao registro das coletas, remessas e transporte de material biológico, do acesso ao recurso genético, seus derivados e CTAs, destinados à pesquisa científica ou tecnológica ou à bioprospecção; de pessoas físicas ou jurídicas nacionais que realizem as atividades descritas acima; de solicitações e concessões de licença ou autorizações a pessoas jurídicas estrangeiras para realizar as atividades acima; e de coleções ex situ.
2) O Cadastro Nacional de Acesso aos Recursos Genéticos e aos Conhecimentos Tradicionais Associados CNGEN, que deverá ser implementado e administrado pelo órgão executivo do CGEN e vinculado ao MMA, destinado ao registro das atividades de acesso ao recurso genético, aos seus derivados ou ao CTA e informações relacionadas.

3) O Cadastro Nacional da Agrobiodiversidade $\mathrm{CNAB}$, que será implementado e administrado pelo órgão gestor dos recursos genéticos provenientes da agrobiodiversidade (AgroBio), que também será criado pelo APL. O AgroBio será uma unidade administrativa do MAPA. A finalidade deste cadastro será o registro das atividades de acesso ao recurso genético e seus derivados e de remessa e transporte de material biológico, provenientes da agrobiodiversidade; das atividades de acesso ao conhecimento tradicional associado relevantes à agricultura ou alimentação; de coleções ex situ de bancos de germoplasma e de todas as formas de preservação e conservação de material biológico proveniente da agrobiodiversidade; e de pessoa física ou jurídica que realiza atividades relativas ao recurso genético ou aos seus derivados, provenientes da agrobiodiversidade, e aos conhecimentos tradicionais relevantes à agricultura ou alimentação.

A criação desses três cadastros, cada um vinculado a um Ministério, reflete a falta de consenso entre os Ministérios envolvidos na elaboração do APL, no sentido de criação de um cadastro único. Essa proliferação de cadastros, segundo a SBPC, em sua publicação Jornal da Ciência (2008), causará confusão e, em muitos casos, repetição de procedimentos, aumentando desnecessariamente a burocracia para o registro de projetos de pesquisa. Por essa razão, uma das propostas feitas pela SBPC durante a consulta pública do APL foi a unificação desses cadastros, com um mínimo de informações para conhecimento das atividades de pesquisa. Pela proposta, esse cadastro único deverá ser implementado e gerido pelo $\mathrm{CNPq}$, no âmbito do MCT.

O APL dispõe também sobre a possibilidade de sigilo das informações registradas, quando solicitado pelo requerido, excetuando-se os casos em que sua divulgação seja necessária para proteção de interesse público, da saúde pública, do meio ambiente ou de direitos das comunidades indígenas, quilombolas ou tradicionais provedoras de conhecimentos tradicionais associados. Entretanto, não deixa claro a quem caberá essa decisão sobre a necessidade de publicidade ou não. Ao que parece, a princípio, tal responsabilidade seria do órgão administrador do cadastro. 


\section{Fundo de Repartição de Benefícios dos Recursos Genéticos e dos Conhecimentos Tradicionais Associados (FURB)}

O anteprojeto de lei prevê a criação do Fundo de Repartição de Benefícios do Recurso Genético e do Conhecimento Tradicional Associado (FURB), com natureza financeira e vinculado ao MMA. A finalidade do FURB é, entre outras, beneficiar as comunidades que compartilham de um mesmo conhecimento tradicional, mas que não façam parte do contrato de acesso e repartição de benefícios desse conhecimento tradicional associado.

Isso poderá ocorrer nos casos em que uma comunidade der o consentimento prévio fundamentado para o acesso ao conhecimento tradicional associado e firmar um contrato sobre esse acesso e a futura repartição de benefícios e outra comunidade não o tiver feito. Neste caso, esta última não será contemplada nesse contrato de repartição de benefícios, entretanto, essa comunidade compartilha dos conhecimentos tradicionais do qual deriva o referido contrato.

O objetivo é que as comunidades que não firmaram o contrato não sejam prejudicadas, pois receberão os benefícios por intermédio do FURB, enquanto as que estabeleceram o contrato terão direito aos benefícios advindos do mesmo, além daqueles provenientes do Fundo.

O gerenciamento do FURB caberá a um comitê gestor, que terá caráter deliberativo e será composto por representantes de órgãos e entidades do Poder Executivo e da sociedade civil, entretanto, a sua presidência caberá exclusivamente ao representante do órgão federal responsável pela política de meio ambiente, que é o Ministério do Meio Ambiente. Com essa previsão, o anteprojeto de lei possibilita que representantes das comunidades indígenas, quilombolas e tradicionais, que na verdade serão os maiores interessados neste Fundo, façam parte da gestão do mesmo, com direito a voz e voto. Contudo, para evitar futuros equívocos, seria interessante que o APL dispusesse a participação dessas comunidades textualmente.

$\mathrm{O}$ anteprojeto de lei prevê ainda que os recursos do FURB serão destinados na proporção de cinquenta por cento para ações prioritárias na área de conservação e uso sustentável da biodiversidade e agrobiodiversidade e de proteção e valorização da sociodiversidade, e cinquenta por cento para ações que promovam a sustentabilidade social, econômica, ambiental e cultural de comunidades indígenas, quilombolas e tradicionais.

\section{Adoção do princípio da hipossuficiência}

Outra novidade trazida pelo anteprojeto de lei, em relação à Medida Provisória 2.186-16/01, é a incorporação do princípio da hipossuficiência, no caso das comunidades indígenas, quilombolas e tradicionais. Tal princípio foi consagrado pelo Código de Defesa do Consumidor - CDC, Lei $\mathrm{n}^{\circ}$ 8.078/90 (BRASIL, 1990). Segundo os ensinamentos de Grinover et al. (2001), hipossuficiente é considerado aquele cuja vulnerabilidade esteja acima da média, ou seja, os ignorantes e de pouco conhecimento, de idade pequena ou avançada, de saúde frágil, bem como aqueles cuja posição social não lhes permita avaliar com adequação o produto ou serviço que estão adquirindo.

Nesse sentido, o anteprojeto de lei estabelece mecanismos para facilitar a defesa dos direitos das comunidades indígenas, quilombolas e tradicionais no tocante aos conhecimentos tradicionais associados e recursos genéticos ou a seus derivados em processo civil, inclusive com a inversão do ônus da prova em favor dos titulares dos conhecimentos tradicionais associados. Tal medida certamente facilitará sua defesa em juízo, diante da falta de condições materiais e das especificidades culturais desses povos e comunidades.

A inversão do ônus da prova é uma facilitação dos direitos dessas comunidades e se justifica como uma norma que visa garantir o equilíbrio da relação contratual face a vulnerabilidade desses atores.

De acordo com Nery Jr. (2009), a prova é elemento essencial para a resolução dos conflitos e está diretamente ligada ao princípio do devido processo legal, assegurado pelo art. $5^{\circ}$, LIV da Constituição Federal. Silva (2003) aponta as regras do ônus da prova como dominantes do nosso sistema probatório, onde à parte que alega a existência de determinado fato incumbe o ônus da prova para conseguir que sua pretensão seja atendida e que seja reconhecida a verdade dos fatos que alegou.

Ao se reconhecer a vulnerabilidade das comunidades indígenas, quilombolas e tradicionais, está se buscando, nos dizeres de Nery Jr. (2009), a paridade das partes no processo no seu sentido efetivo e não somente a igualdade jurídica formal, uma vez que esta última seria facilmente alcançável com a adoção de regras gerais estáticas. Assim, assevera o autor (p. 104): "Tratar igualmente os iguais e desigualmente os desiguais, é a substância do princípio da isonomia”. Princípio este já consagrado por Rui Barbosa. 


\section{Onovo Conselho de Gestão dos Recursos Genéticos}

Além de rebatizar o CGEN para Conselho de Gestão dos Recursos Genéticos, como visto anteriormente, o anteprojeto de lei acrescenta ao novo CGEN o caráter consultivo e multidisciplinar, somando-se ao caráter deliberativo e normativo que já é dado pela Medida Provisória.

Sobre a composição desse novo CGEN, o anteprojeto não deixa explícito quem fará parte do Conselho, como o faz a MP 2.186-16/01, que prevê a composição do Conselho de Gestão do Patrimônio Genético exclusivamente por representantes de órgãos e entidades da Administração Pública Federal. Entretanto, o APL expõe que representantes da sociedade civil, incluídas as comunidades científica e do setor público, poderão ser convidados para subsidiar os trabalhos do CGEN em caráter excepcional e sem direito a voto. Ao que parece, a representação da sociedade civil continuará sendo excluída do CGEN, uma vez que esta permanecerá sem voto.

$\mathrm{O}$ anteprojeto de lei atribui ao CGEN propor, monitorar e avaliar a execução de políticas relacionadas aos recursos genéticos, aos seus derivados e aos conhecimentos tradicionais associados. Nesse sentido, amplia a competência do CGEN em relação à MP, uma vez que esta estabelece que compete ao CGEN apenas coordenar a implementação de políticas para a gestão do patrimônio genético, ficando omissa sobre os conhecimentos tradicionais associados.

A Medida Provisória atribui ao CGEN estabelecer critérios para a criação de bases de dados para o registro de informação sobre conhecimento tradicional associado. Essa atribuição foi retirada pelo APL e, a princípio, não foi delegada a nenhum outro órgão, ficando então a criação de um banco de dados dessa natureza desprovida de critérios predefinidos.

\section{Acesso a conhecimentos tradicionais associados relevantes à alimentação e agricultura}

$\mathrm{O}$ acesso a esses conhecimentos tradicionais para qualquer finalidade está condicionado ao prévio cadastro do interessado no $\mathrm{CNAB}$ e depende de consentimento prévio fundamentado da comunidade indígena, quilombola ou tradicional. Entretanto, há uma previsão no APL de que o AgroBio poderá solicitar ao MAPA a expedição de portaria que defina situações excepcionais, com base no interesse público, em que este cadastro possa ser dispensado.
Este conceito de interesse público é extremamente subjetivo, podendo ser utilizado tanto para atenuar conflitos como para explorar o conhecimento das comunidades sem o seu devido consentimento prévio fundamentado. Por este motivo, tal conceito não deveria constar no corpo do dispositivo legal.

Certamente, um dos pontos nevrálgicos do anteprojeto de lei se refere à distinção entre conhecimentos tradicionais associados e conhecimentos tradicionais associados relevantes à alimentação e agricultura, pois se deve atentar para a possibilidade de haver situações de conhecimentos tradicionais associados que não sejam diretamente relevantes à alimentação e agricultura, mas que possam vir a ser relevantes de forma indireta. Possivelmente, nesses casos o mesmo projeto deverá ser registrado nos três cadastros. Além disso, como será visto a seguir, as pessoas que realizarão o acesso terão que estar cadastradas no CNGEN e no CNACT.

Um ponto obscuro no capítulo sobre esse tema é a falta de especificação sobre quem poderá realizar essa modalidade de acesso. Há uma especificação de que o acesso só poderá ser realizado por pessoas jurídicas nacionais ou estrangeiras ou por brasileiros profissionalmente habilitados nas áreas biológicas, humanas e afins e todos terão que estar cadastrados no CNGEN e no CNACT. Contudo, o texto impõe um condicionante ao acesso realizado por pessoa física ou jurídica estrangeira, mas não específico sobre os nacionais. Dessa forma, pessoa física estrangeira poderá ter acesso a estes conhecimentos, o que não ocorre quando se trata de conhecimentos tradicionais associados à diversidade biológica.

Esses pontos divergentes podem demonstrar a falta de interação entre os Ministérios envolvidos na elaboração do texto. Ao que parece, houve um alinhamento entre o MMA e o MCT, mas não necessariamente entre esses dois e o MAPA.

\section{Definição de conhecimentos tradicionais asso- ciados e conhecimentos tradicionais associados relevantes à alimentação e agricultura}

No artigo referente às definições dos termos empregados no texto, o APL define conhecimentos tradicionais associados e conhecimentos tradicionais associados relevantes à alimentação e agricultura. $\mathrm{O}$ ponto comum nas duas definições é que consideram as duas formas como 
"todo conhecimento, inovação ou prática, individual ou coletiva". A preocupação está no que vem a seguir. Só será enquadrado na definição de conhecimentos tradicionais relevantes à alimentação e agricultura o conhecimento dos agricultores tradicionais, ficando excluído todo o conhecimento sobre o tema que, porventura, seja da titularidade das outras comunidades.

Assim, o acesso a esses mesmos conhecimentos, porém provenientes de comunidades que não sejam os agricultores tradicionais, será regido pelo capítulo de acesso a conhecimentos tradicionais associados. Isso irá gerar uma infinidade de dúvidas e críticas, que levarão a uma insegurança jurídica totalmente indesejável na constituição de um marco legal.

Outra definição que merece atenção é relativa ao termo associado. Conhecimento tradicional associado, nos termos estabelecidos pelo anteprojeto de lei, é o associado às propriedades, usos e características da diversidade biológica. Já o conhecimento tradicional relevante à alimentação e agricultura está associado à conservação e ao uso agrícola ou alimentar de recursos genéticos da agrobiodiversidade.

O que se observa é que, enquanto a definição de conhecimento tradicional associado o vincula mais corretamente à diversidade biológica, a definição de conhecimento tradicional associado relevante à alimentação e agricultura incorre em equívoco semelhante ao da Medida Provisória 2.186-16/01 ao vinculá-lo apenas aos recursos genéticos.

Essa divergência mais uma vez demonstra que tais conceitos foram elaborados por atores diferentes e que não houve diálogo entre ambos.

\section{Proteção e acesso aos conhecimentos tradicionais associados}

\section{Direitos originários}

O anteprojeto de lei destina um capítulo exclusivo à proteção e ao acesso aos conhecimentos tradicionais associados. Logo no primeiro artigo deste capítulo, o APL reconhece que as comunidades indígenas, quilombolas e tradicionais possuem direitos originários sobre seus conhecimentos tradicionais.

Na ponderação de Antunes (1998), tal direito originário "[...] é direito precedente e superior a qualquer outro que, eventualmente, se possa ter constituído [...]".
A Constituição da República de 1988, no caput de seu artigo 231, já havia reconhecido os direitos originários dos índios sobre as terras que tradicionalmente ocupam. O APL estendeu esses direitos originários, garantidos pela Carta Magna, aos conhecimentos tradicionais, não só dos índios, mas dos quilombolas e das comunidades que se autorreconheçam como tradicionais.

Segundo Barbosa (2001), o objetivo do legislador constituinte é esclarecer que o Estado brasileiro reconhece aos índios direitos territoriais existentes antes mesmo da criação do próprio Estado brasileiro, por isso, a utilização da expressão "direitos originários".

\section{Direitos morais e patrimoniais}

O texto do APL inspira-se na legislação autoral (Lei 9.610/95) ao diferenciar direitos morais e patrimoniais sobre os conhecimentos tradicionais associados. Dessa forma, os direitos morais serão inalienáveis, ou seja, mesmo que o conhecimento tradicional seja compartilhado, adotadas as exigências de consentimento prévio e fundamentado, e estipulado o contrato para a repartição de benefícios oriundos da comercialização por terceiros de produtos obtidos através dos seus conhecimentos, as comunidades indígenas, quilombolas e tradicionais conservam o seu direito moral sobre tais conhecimentos, impenhoráveis pela própria característica de serem inalienáveis e irrenunciáveis, o que significa que, mesmo que sejam induzidos a um erro por terceiros, as comunidades indígenas, quilombolas e tradicionais não poderão renunciar a seus direitos morais.

O texto do APL não fala expressamente em imprescritibilidade, mas sim em prazo indeterminado, o que significa que não cabe prescrição temporal para esses direitos morais e que eles poderão ser reclamados no judiciário a qualquer tempo.

Entretanto, o anteprojeto não conceitua o que seriam os direitos morais das comunidades indígenas, quilombolas e tradicionais. Nesse sentido, Barbosa (2002) sugere que esses direitos morais sejam aqueles expressos no art. $9^{\circ}$, I da MP 2.186-16/01, que é o direito de ter indicada a origem do acesso ao conhecimento tradicional associado em todas as publicações, utilizações, explorações e divulgações dos produtos a ele referentes. Mota (2009) esclarece que esse direito não é similar ao direito moral do autor na forma do art. 24 da Lei 9.610/98, mas sim de outra modalidade, criada pela Medida Provisória, referente ao direito moral do titular dos conhecimentos tradicionais associados. 
Quanto aos direitos patrimoniais sobre os conhecimentos tradicionais associados das comunidades indígenas, quilombolas e tradicionais, o texto do anteprojeto os tipifica como impenhoráveis e irrenunciáveis. Em relação ao tempo que deve perdurar a proteção, determina o texto que eles devem perdurar enquanto subsistirem as características que permitiram a tais conhecimentos serem identificados como indígenas, quilombolas ou tradicionais, dentro dos contextos culturais em que foram gerados.

Esta determinação não é exata e deixa margem para várias dúvidas e discussões, permitindo, esta lacuna, que as partes negociem livremente o período de remuneração proveniente do uso dos mesmos, não avançando em relação à Medida Provisória.

Na visão de Barbosa (2002), tal direito patrimonial estaria diretamente relacionado ao consentimento prévio informado, pois seria exclusivo de impedir terceiros não autorizados de realizar testes, pesquisas ou exploração; divulgar, transmitir ou retransmitir dados ou informações que integram ou constituem o conhecimento tradicional associado; perceber benefícios, direta ou indiretamente, desse conhecimento, cujos direitos não são de sua titularidade.

\section{Alteração das expressões detentores e possuidores para titulares}

A Declaração do Rio Negro (INBRAPI, 2007), firmada em dezembro de 2007, consiste em uma manifestação do movimento indígena sobre o anteprojeto de lei que foi submetido à consulta pública pela Casa Civil. Essa declaração discorda da utilização das expressões "detentores" e "possuidores" de conhecimentos tradicionais, em referência aos povos indígenas. O APL deve reconhecer que são "titulares" dos conhecimentos tradicionais que integram suas culturas. Nesse sentido, sugerem a alteração dos dispositivos que utilizam os termos mencionados. Solicitam também que seja incluída uma disposição reconhecendo o domínio sobre seus saberes, inovações e práticas e outra que inclua o direito dos povos indígenas de dispor dos seus conhecimentos, inovações e práticas inerentes aos direitos que um titular pode exercer sobre o bem que lhe pertence.

Corroborando tal posição, Kamau (2009) ressalta que o artigo 8 “j” da Convenção sobre a Diversidade Biológica identifica explicitamente as comunidades indígenas e locais como os proprietários do conhecimento tradicional.

Segundo o Dicionário Aurélio, "detentor" é um depositário, ou seja, aquele que recebe em depósito (FERREIRA,
1986). Nesse caso, não é o proprietário, apenas guarda consigo o conhecimento. Segundo tal descrição, o artigo 1.198 do Código Civil Brasileiro define detentor como sendo "aquele que, achando-se em relação de dependência para com outro, conserva a posse em nome deste e em cumprimento de ordens ou instruções suas" (BRASIL, 2002). Esse, porém não é o sentido que os indígenas esperam da norma jurídica que disciplina o acesso e o uso de conhecimentos tradicionais. Os povos indígenas, por meio de seus representantes, afirmam serem "proprietários" de seus saberes e, cada vez mais, exigem que esse reconhecimento seja expresso na legislação que ora se discute.

\section{Direito de negar o acesso}

A MP, em seu art. $9^{\circ}$, relaciona alguns direitos garantidos às comunidades indígenas e locais que criam, desenvolvem, detêm ou conservam o conhecimento tradicional associado e entre eles não está especificado o direito dessas comunidades de negar o acesso aos seus conhecimentos tradicionais associados, o que levanta dúvidas sobre o tema. Apenas os povos indígenas possuem premissa legal de negar o acesso ao seu conhecimento, por estes possuírem o direito constitucional ao usufruto dos recursos naturais (artigo 231, § 2 $2^{\circ}$ CRFB/88 - BRASIL, 1988).

$\mathrm{O}$ anteprojeto de lei adota o princípio do consentimento prévio informado e, com isso, confere às comunidades indígenas, quilombolas e tradicionais o direito de negar o acesso aos seus conhecimentos tradicionais associados. Castilho (2004) salienta que este direito de negar o acesso também é expressamente reconhecido na legislação da Costa Rica que trata sobre o tema.

\section{Previsão de acesso a conhecimentos tradicionais associados em banco de dados}

A Medida Provisória 2.186-16/01 estabelece, em seu artigo $8^{\circ}, \S 2^{\circ}$, que o conhecimento tradicional associado poderá ser objeto de cadastro conforme disposição do CGEN ou de legislação específica. Até o momento essa é a única previsão legislativa para a elaboração de um banco de dados que contenha os conhecimentos tradicionais associados.

Sobre esse tema, o anteprojeto de lei faz alguns avanços. Na definição de conhecimento tradicional associado, prevê que estes possam estar inseridos em bancos 
de dados, o que não os descaracteriza como conhecimentos tradicionais associados.

Em um segundo momento, o APL dita regras sobre o acesso aos conhecimentos tradicionais associados, que estejam eventualmente em um banco de dados, com a finalidade de bioprospecção, elaboração ou desenvolvimento de produtos comerciais, antevendo a necessidade de cadastro do projeto no CNGEN e CNACT, comprovação de consentimento prévio fundamentado do provedor do conhecimento tradicional associado e assinatura de contrato de acesso e repartição de benefícios, que deverão ser obtidos junto a uma das comunidades identificadas.

Quando o acesso ao banco de dados for exclusivamente com fins de pesquisa científica, sem fins comerciais, não haverá necessidade de licença, apenas notificação do projeto pelo responsável no CNGEN e no CNACT.

$\mathrm{O}$ anteprojeto de lei reconhece, também, que os direitos relacionados aos conhecimentos tradicionais associados independem de quaisquer atos constitutivos do poder público. Isso significa que qualquer mecanismo de sistematização desses conhecimentos, seja em bancos de dados, inventários, registros, cadastros etc., será sempre subsidiário, facultativo e de natureza exclusivamente declaratória, não condicionante para a proteção dos conhecimentos tradicionais associados.

Nos casos de acesso aos conhecimentos tradicionais associados para a constituição de banco de dados, registros, inventários ou outras formas de sistematização, para fins exclusivamente científicos, não será necessária a licença, apenas o cadastramento do projeto relativo a essa finalidade no CNGEN e no CNACT.

Quando ocorrer acesso aos conhecimentos tradicionais associados por intermédio de bancos de dados, registros, inventários ou outras formas de sistematização, com titular identificável, haverá a necessidade do consentimento prévio fundamentado e do contrato de repartição de benefícios com pelo menos uma das comunidades titulares de tal conhecimento para que possa ser solicitada a licença junto ao CGEN.

Se não houver como identificar o titular do acesso, será necessário para obter a licença apenas o cadastro no CGEN e a repartição dos benefícios, se houver, irá para o Fundo de Repartição de Benefícios dos Recursos Genéticos e dos Conhecimentos Tradicionais Associados (FURB). Quando o acesso for aos conhecimentos tradicionais associados disseminados, não haverá a obrigatoriedade da licença, exceto se este acesso for realizado por empresa ou instituição estrangeira.

\section{Sanções}

Havia uma grande expectativa de que houvesse no texto do anteprojeto de lei, no capítulo que trata das sanções, a previsão de penas restritivas de liberdade que atingissem inclusive pessoa jurídica, da mesma forma que a lei de crimes ambientais, o que, de acordo com Varella (2004), seria uma importante contribuição para acabar com a impunidade contra os crimes ambientais e a utilização indevida do material genético e dos conhecimentos tradicionais associados no Brasil.

Entretanto, não é isso que se observa na análise do texto em questão. O APL segue a Medida Provisória 2.186-16/01 e prevê apenas sanções administrativas para as infrações. Nesse sentido, o anteprojeto não evolui normativamente.

Botton (2008), ao informar os principais aspectos da manifestação da Associação Brasileira de Propriedade Intelectual (ABPI) sobre a consulta pública do anteprojeto de lei, ressalta que o mesmo prevê em seu texto a nulidade da patente cujo objeto tenha sido obtido em decorrência de acesso a recurso genético, aos seus derivados ou ao conhecimento tradicional associado sem observância das disposições do referido projeto de lei. AABPI considera que tal previsão não está de acordo com a Convenção da União de Paris (CUP), com o Acordo sobre Aspectos dos Direitos de Propriedade Intelectual relacionados ao Comércio (TRIPS) e com a Lei de Propriedade Industrial no 9.279/96 e tampouco oferece oportunidade administrativa de sanar o vício e/ou os possíveis erros ocorridos durante o processo de autorização. Além disso, a nulidade de tais direitos provavelmente resultará em uma redução da repartição justa e equitativa de benefícios, que, no parecer da ABPI, vem a ser um dos principais objetivos do APL.

A sugestão apresentada pela ABPI é que o anteprojeto de lei contemple a possibilidade de o titular da patente sanar o vício antes que a mesma seja considerada nula. Nesse caso, a proposta é que se considerem penalidades alternativas, tais como a previsão de multa pelo descumprimento da lei ou o aumento de impostos relativos à exploração do objeto da patente. A ABPI recomenda ainda que a penalidade recaia sobre o titular da patente e não sobre os direitos de patente em si. 


\section{Considerações finais}

Ao apresentar o anteprojeto de lei e submetê-lo à consulta pública, o Governo Federal tem como objetivo substituir a Medida Provisória 2.186-16/2001 com uma legislação aprimorada no que se refere à pesquisa e à bioprospecção, além de estabelecer mecanismos para a repartição de benefícios com as comunidades indígenas e tradicionais.

Contudo, ao se observar o volume de críticas advindas dos setores consultados, pode-se constatar que o Governo está longe de alcançar seu objetivo. Um dos motivos que se mostra bem evidente é o conflito de interesses dos diversos setores da sociedade envolvidos no tema do anteprojeto: as comunidades indígenas e tradicionais, a comunidade acadêmica e o setor empresarial, o que dificulta os consensos e atrasa as decisões.

Não se pode contestar que o anteprojeto de lei apresenta várias novidades em relação à atual legislação de acesso ao patrimônio genético, embora nem todas positivas. O APL avança, especialmente no que diz respeito aos conhecimentos tradicionais e à repartição de benefícios. Um exemplo é a ampliação do conceito de conhecimento tradicional associado, abrangendo os acessos a partir de

\section{Referências}

ANTUNES, P. de B. Ação civil pública, meio ambiente e terras indígenas. Rio de Janeiro: Lúmen Júris, 1998.

AZEVEDO, C. M. do A. Acesso aos recursos genéticos - novos arranjos institucionais. In: ENCONTRO DA ASSOCIAÇÃO NACIONAL DE PÓS-GRADUAÇÃO E PESQUISA EM AMBIENTE E SOCIEDADE, 1., Indaiatuba, SP. Anais... Indaiatuba, 2002, p. 1-13. Disponível em: <http://www. anppas.org.br/encontro_anual/encontro1/gt/biodiversidade/ Cristina\%20Maria\%20do\%20Amaral\%20Azevedo.pdf $>$. Acesso em: 05/2011.

BARBOSA, D. B. Biodiversidade, Patrimônio Genético e Propriedade Intelectual. 2002. Disponível em: <http:// www.fepi.ipaam.br/biodiversidade/Artigos $\% 20 \mathrm{Cient} \% \mathrm{C} 3$ $\%$ ADficos/Portugu $\%$ C3\%AAs/Biodiversidade, $\% 20$ Patrim $\%$ C3\%B4nio\%20Gen $\%$ C3\%A9tico $\% 20 \mathrm{e} \% 20$ Propriedade $\% 20$ Intelectual_\%28Denis\%20Borges\%20Barbosa\%20-2002\%29. pdf>. Acesso em: 06/2011. bancos de dados, inventários, publicações e no comércio. Esta noção de conhecimento tradicional associado ex situ inexiste na atual legislação brasileira.

As críticas ao anteprojeto de lei tiveram início na forma como foi disponibilizado para consulta pública, o que dificultou a discussão com a sociedade como um todo e especialmente com as comunidades indígenas e tradicionais, que deveriam ter uma ampla participação, por serem os titulares dos conhecimentos tradicionais associados, na regulamentação de uma lei específica, como determina, inclusive, a Política Nacional de Diversidade.

Entre as diversas críticas apresentadas pelos variados atores, algumas são quase unânimes, como a necessidade de aperfeiçoamento de definições, a criação de um cadastro único que tornará mais simples, direta e transparente a obtenção de autorizações e a participação da sociedade civil com direito a voz e voto na estrutura do novo Conselho de Gestão de Recursos Genéticos.

Nesse sentido, o anteprojeto de lei apresenta a mesma falta grave da Medida Provisória, ao excluir as representações de povos indígenas e tradicionais, bem como as organizações da sociedade civil, dos debates nos fóruns de discussão, onde só poderão participar como convidados, sem poder decisório, alijando-se mais uma vez do processo a instituição da cidadania participativa efetiva.

BARBOSA, M. A. Direito antropológico e terras indígenas no Brasil. São Paulo: Plêiade, 2001.

BENSUSAN, N. Breve histórico da regulamentação do acesso aos recursos genéticos no Brasil. In: LIMA, A.; BENSUSAN, N. Quem cala consente? Subsídios para proteção aos conhecimentos tradicionais. São Paulo: Instituto Socioambiental, 2003. p. 9-16.

BOTTON, L. G. Anteprojeto de Lei e Acesso a Recursos Genéticos e Repartição de Benefícios. Boletim da ABPI, n. 91, p. 3-4, abril/2008.

BRASIL. Constituição da República Federativa do Brasil, de 5 de outubro de 1988. Organização do texto: Guilherme Peña de Moraes. 4. ed. Rio de Janeiro: Lúmen Júris, 2006. 451 p.

Lei 8.078 de 11 de setembro de 1990. Dispõe sobre a proteção do consumidor e dá outras providências. Brasília: DOU de 12/09/1990. 
. Ministério das Relações Exteriores. Divisão de Meio Ambiente. Conferência das Nações Unidas sobre Meio Ambiente e Desenvolvimento: relatório da delegação brasileira. Brasília: Fundação Alexandre de Gusmão; Instituto de Pesquisa de Relações Internacionais, 1993. (Tradução não oficial, publicada como anexo).

. Lei 9.610, de 19 de fevereiro de 1998. Altera, atualiza e consolida a legislação sobre direitos autorais e dá outras providências. Brasília, DOU de 20/02/1998.

Medida Provisória 2186-16, de 23 de agosto de 2001. Regulamenta o inciso II do $\S 1^{\circ}$ e o $\S 4^{\circ}$ do art. 225 da Constituição, os arts. $1^{\circ}, 8^{\circ}$, alínea "j", 10, alínea "c", 15 e 16, itens 3 e 4 da Convenção sobre Diversidade Biológica, dispõe sobre $o$ acesso ao patrimônio genético, a proteção e o acesso ao conhecimento tradicional associado, a repartição de benefícios e o acesso à tecnologia e transferência de tecnologia para sua conservação e utilização, e dá outras providências. Brasília, DOU de 24/08/2001.

Lei 10.406, de 10 de janeiro de 2002. Institui o Código Civil. Brasília: DOU de 11/01/2002.

. Decreto n. 6.040, de 7 de fevereiro de 2007. Institui a Política Nacional de Desenvolvimento Sustentável dos Povos e Comunidades Tradicionais. Brasília, DOU de 8/02/2007.

CASTILHO, E. W. V. de. Parâmetros para o regime jurídico sui generis de proteção ao conhecimento tradicional associado a recursos biológicos e genéticos. In: MEZZAROBA, O. (Org.). Humanismo latino e Estado no Brasil. Florianópolis: Fundação Boiteux, Fondazione Casamarca, 2003. p. 453-472.

. Diversidade biológica: questões controvertidas na proteção do conhecimento tradicional. Meio Ambiente - Grandes Eventos, Brasília: ESMPU, v. 1, p. 183-187, 2004.

CONFERÊNCIA DAS NAÇÕES UNIDAS SOBRE MEIO AMBIENTE E DESENVOLVIMENTO. Convenção sobre Diversidade Biológica. 1992. Disponível em: $<$ http://www. onu-brasil.org.br/doc_cdb.php>. Acesso em: 05/2011.

FERREIRA, A. B. de H. Novo Dicionário Aurélio da Língua Portuguesa. 2. ed. Rio de Janeiro: Nova Fronteira, 1986.

FERREIRA, S. N.; CLEMENTINO, A. N. R. Proteção dos conhecimentos tradicionais associados à biodiversidade. Revista Jurídica, v. 8, n. 81, p. 1-7 Brasília. 2006. Disponível em: $<$ http://www.planalto.gov.br/ccivil_03/revista/rev_81/Artigos/ Simone_rev81.htm>. Acesso em: 05/2011.

FONTES, C. O anteprojeto de lei de acesso aos recursos genéticos e proteção aos conhecimentos tradicionais foi elaborado no ano passado com a participação de diversos setores, entre os quais as organizações não governamentais, representadas pelo Instituto Socioambiental (ISA). Está há cerca de sete meses na Casa Civil, sendo modificado a portas fechadas. Biodiversidade e Conhecimentos Tradicionais: mais proteção já. Instituto Socioambiental - ISA, julho/2004. Disponível em: <http:// www.socioambiental.org/esp/tradibio/>. Acesso em: 05/2011.

GRINOVER, A. P.; BENJAMIN, A. H. de V.; FINK, D. R.; FILOMENO, J. G. B.; WATANABE, K.; NERY JÚNIOR, N.; DENARI, Z. Código Brasileiro de Defesa do Consumidor comentado pelos autores do anteprojeto. 7. ed. rev. e ampl. Rio de Janeiro: Forense Universitária, 2001.

INBRAPI. Declaração do Rio Negro sobre consulta pública do projeto de lei sobre acesso e proteção aos conhecimentos tradicionais dos povos indigenas. São Gabriel da Cachoeira, AM, 05 de dezembro de 2007. Disponível em: <http://www. inbrapi.org.br/maracaonline/index.php?option=com_content $\&$ view $=$ section \&layout $=$ blog\&id $=9 \&$ Itemid $=15 \&$ lang $=p t>$. Acesso em: 05/2011.

KAMAU, E. C. A importância do artigo 8 “j” da CDB, o problema do conhecimento tradicional disseminado e a experiência do Quênia. In: KISHI, S. A. S.; KLEBA, J. B. (Coord.). Dilemas do acesso à biodiversidade e aos conhecimentos tradicionais. Direito, política e sociedade. Belo Horizonte: Fórum, 2009. p. 157-190.

KISHI, S. A. S. Tutela jurídica do acesso à biodiversidade no Brasil. Meio Ambiente - Grandes Eventos, Brasília: ESMPU, v. 1, p. 167-179, 2004.

Consentimento prévio informado no Brasil. In: ; KLEBA, J. B. (Coord.). Dilemas do acesso à biodiversidade e aos conhecimentos tradicionais. Direito, política e sociedade. Belo Horizonte: Fórum, 2009. p. 191-216.

. Visão crítica sobre a Convenção da Biodiversidade - seus objetivos, soberania estatal e acesso ao conhecimento tradicional. Revista Internacional Direito e Cidadania REIO, n. 09/2011. Disponível em: <http://www.reid.org. $\mathrm{br} / ? \mathrm{CONT}=00000155>$. Acesso em: 05/2011.

LEWINSOHN, T. M.; PRADO, P. I. Quantas espécies há no Brasil? Megadiversidade, v. 1, n. 1, p. 36-42, 2005.

MACHADO, C. J. S.; GODINHO, R. de S. Acesso à Diversidade Biológica e aos Conhecimentos Tradicionais Associados no Brasil: um estudo sobre a sua regulamentação. Revista Forense, Rio de Janeiro, v. 413, p. 51-69, 2011.

MACHADO, P. A. L. Direito Ambiental Brasileiro. 17. ed. São Paulo: Malheiros, 2009. 
MINISTÉRIO DO MEIO AMBIENTE. CONSELHO DE GESTÃO DO PATRIMÔNIO GENÉTICO - CGEN. Orientação Técnica $n$. 1, de 24 de setembro de 2003. Esclarece os conceitos de acesso e de remessa de amostras de componentes do patrimônio genético. Brasília, DOU de 24/10/2003.

MOTA, M. J. P. da. Direitos intelectuais coletivos e função social da propriedade intelectual: os conhecimentos tradicionais associados à biodiversidade. In: (Coord.). Função social do Direito Ambiental. Rio de Janeiro: Elsevier, 2009. p. 90-153.

NERY JR., N. Princípios do Processo Civil na Constituição Federal. Processo Civil, penal e administrativo. 9. ed. São Paulo: Revista dos Tribunais, 2009.

NOVION, H.; MATHIAS, F. PL de acesso a recursos genéticos é submetido a consulta pública. Notícias Socioambientais, Instituto Socioambiental - ISA, 2007. Disponível em: $<$ http:// www.socioambiental.org/nsa/detalhe?id=2573>. Acesso em: 16/05/2011.

PEREIRA, B. E.; DIEGUES, A. C. Conhecimento de populações tradicionais como possibilidade de conservação da natureza: uma reflexão sobre a perspectiva da etnoconservação. Desenvolvimento e Meio Ambiente, Curitiba: Editora UFPR, n. 22, p. 37-50, jul./dez. 2010.

PROGRAMA DE POLÍTICA E DIREITO SOCIOAMBIENTAL - Instituto Socioambiental. Anteprojeto de lei de acesso a recursos genéticos e conhecimentos tradicionais. Biodiversidade e conhecimentos tradicionais. Mais proteção já. ISA - Instituto Socioambiental. 2004. Disponível em: $<$ http://www. socioambiental.org/esp/tradibio/proscontras.html>. Acesso em: 15/05/2011.

PRÓ-REITORIA DE PESQUISA. Universidade de Campinas - Unicamp. Serviço de Patrimônio Genético. Breve histórico: regulamentação (internacional, nacional e institucional) do acesso aos recursos genéticos da biodiversidade. 2010. Dispo- nível em: $<$ http://www.prp.unicamp.br/patgen/historico.php $>$. Acesso em: 21/05/2011.

SANTILLI, J. Socioambientalismo e novos direitos: proteção jurídica à diversidade biológica e cultural. São Paulo: Peirópolis, 2005.

. O Tratado Internacional sobre Recursos Fitogenéticos para Alimentação e Agricultura (TIRFA) e a sua implementação no Brasil. In: KISHI, S. A. S.; KLEBA, J. B. (Coord.). Dilemas do acesso à biodiversidade e aos conhecimentos tradicionais. Direito, política e sociedade. Belo Horizonte: Fórum, 2009. p. 253-274.

SILVA, O. A. B. da. Curso de Processo Civil. Processo de Conhecimento, v. 1. 6. ed. São Paulo: Revista dos Tribunais, 2003.

SOCIEDADE BRASILEIRA PARA O PROGRESSO DA CIÊNCIA - SBPC. Pesquisadores debatem acesso a recursos genéticos. Jornal da Ciência, JC. e-mail 3450, de 15 de fevereiro de 2008. Disponível em: $<$ http://www.jornaldaciencia.org. br/Detalhe.jsp?id=54288>. Acesso em: 16/05/2011.

SZPILMAN, M. Biodiversidade - As nações mais ricas em diversidade do planeta. Informativo Instituto Ecológico Aqualung, n. 20, p. 1-2, julho/agosto 1998. Disponível em: <http:// www.institutoaqualung.com.br/info_biodiversidade $23 . \mathrm{html}>$. Acesso em: 19/05/2011.

VARELLA, M. D. Algumas ponderações sobre as normas de controle do acesso aos recursos genéticos. In: CUREAU, S. (Org.). Série Grandes Eventos - Meio Ambiente. Brasília: ESMOU, v. I, p. 121-157, 2004.

VIEIRA, I. C. G. Museu Goeldi: "É urgente liberar a pesquisa básica sobre a biodiversidade brasileira". Jornal da Ciência, $J C$, Sociedade Brasileira para o Progresso da Ciência - SBPC. e-mail 3459, de 28 fevereiro 2008. Disponível em: <http:// www.jornaldaciencia.org.br/Detalhe.jsp?id $=54541>$. Acesso em: 21/05/2011. 